\title{
Enunciación
}

http://revistas.udistrital.edu.co/ojs/index.php/enunc

\section{En torno al proceso adaptativo de obras literarias al cine}

\author{
Around the adlaptive process of literary works to fillm
}

\author{
Juan Ramón Ferrera Vaillant ${ }^{1}$
}

Para citar este artículo: Ferrera Vaillant, J.R. (2016). En torno al proceso adaptativo de obras literarias al cine. Enunciación, 21(2) 226-236.

Recibido: 3-febrero-2016 / Aprobado: 7-diciembre-2016

\section{Resumen}

El presente artículo parte de una revisión bibliográfica que permitió determinar los principales presupuestos teóricos para el estudio de las adaptaciones fílmicas de textos literarios, y así obtener una visión más completa de cuáles han sido los enfoques y perspectivas más recurrentes en el tratamiento brindado a estos temas por los estudiosos.

Palabras clave: literatura, cine, adaptaciones para cine.

\begin{abstract}
This article is based on a literature review, which identified the main theoretical assumptions for the study of the film adaptations of literary texts, in order to obtain a more complete picture of what approaches and perspectives have been the most frequent in the treatment given to these issues by scholars.
\end{abstract}

Keywords: literature, film media, film adaptation.

1 Docente en la Universidad de La Habana, Cuba. Vicedecano de Investigación, Posgrado y Relaciones Internacionales. Correo electrónico: juan.rfv@fenhi.uh.cu 


\section{INTRODUCCIÓN}

Las relaciones entre la literatura y el cine están caracterizadas por influencias recíprocas que se generan durante el acto creativo y van desde la influencia del cine en la obra de los escritores, sus incursiones en el campo de la crítica, la guionística o, inclusive, la dirección de cine, hasta los procesos de naturaleza textual que es posible verificar cuando la cinta está inspirada en una obra literaria. Y, de esta suerte, es posible también afirmar que dichas relaciones, en la medida en que cobran más y nuevos matices (según los casos específicos), pueden ser estudiadas desde enfoques distintos.

La literatura ha hecho partícipe a la cinematografía de gran parte de sus mejores historias. Comparten estas artes muchos de sus procedimientos narrativos, y las múltiples relaciones que establecen han sido objeto, históricamente, del estudio de los investigadores; que han debido esperar primero por la madurez del séptimo arte y, más tarde, por la tolerancia en los espacios ganados tradicionalmente para la discusión científico-literaria sobre estos temas.

En la actualidad se abre la polémica a zonas aún inexploradas, se sistematizan los conocimientos acumulados en otras y se especula en torno a la posible aplicación de enfoques intermediales y perspectivas multidisciplinarias. Entre todos los temas a debatir, el de las adaptaciones de obras literarias al cine es uno de los que mayores motivaciones despierta por la periodicidad con que ha avivado el intercambio entre investigadores y críticos. Importantes centros de la enseñanza superior en varias partes del mundo han creado espacios teóricos que profundizan en la naturaleza de las adaptaciones cinematográficas, así como en las teorías y métodos para su análisis desde ópticas tan distintas como el análisis estético del guion cinematográfico, las teorías sobre narratividad y las variantes narrativas del cine contemporáneo, los trasvases culturales entre literatura y cine, el análisis del filme como texto e intertexto, y las estrategias semióticas para su comprensión, entre otras, que han podido concretarse lo mismo en ponencias, artículos científicos y tesis doctorales.

Hallar los criterios vertidos por algunos escritores, directores de cine y autores de habla hispana, entre los que se cuentan Ángel Vilanova, María Elena Rodríguez Martín, María Lourdes Cortés, Jorge Urrutia, Marcela Patricia Restom Pérez y José Luis Sánchez Noriega -quien ha elaborado una tipología de las adaptaciones y cinco modelos de análisis por géneros-, así como la relectura de los clásicos del género, como Pío Baldelli -a la luz de los enfoques contemporáneos sobre temas ya abordados por él en los años sesenta-, constituyeron incentivos que motivaron este artículo.

La problemática de las transposiciones de obras literarias al cine es uno de los aspectos que, dentro del mundo del cine, atrae el interés de los especialistas. Los enfoques y criterios vertidos son muy diversos, no solo por las particularidades de sus perspectivas, sino también por sus grados de objetividad y agudeza. Puede afirmarse que entre las muchas posibilidades de estudio que ofrecen las relaciones literatura/cine, las más importantes y frecuentemente citadas por la crítica cinematográfica son los estudios relacionados con la adaptación de la literatura al cine, por lo que este artículo tiene como objetivo explicar los criterios en torno a las adaptaciones fílmicas de textos literarios, destacándose los principales autores y enfoques.

\section{METODOLOGÍA}

Este artículo se sustenta en lo fundamental en la perspectiva cualitativa como modalidad y paradigma epistemológico. Se parte de la dialéctica materialista como método general y se emplean fundamentalmente métodos teóricos como:

- Análisis-síntesis: presente en la investigación para determinar los límites del objeto de estudio, así como los elementos de descomposición del proceso descrito y sus partes. 
- Inducción-deducción: establece los razonamientos generales y particulares del objeto de investigación y el campo de acción.

\section{RESULTADOS Y DISCUSIÓN}

Dentro de la enmarañada maleza de posiciones, tendencias y procederes en el campo de la crítica relacionada con el tema de las adaptaciones de obras literarias al cine, se deslindan tres puntos de vista fundamentales que coinciden con el papel que desempeñan sus gestores en la realización. Así, se distinguen tres puntos de vista: 1) el del escritor, 2) el del director y 3) el del crítico o investigador sobre estas materias.

De dichas posturas se deslinda un grupo de tendencias definidas por la estimación, o no (por parte de escritores, críticos o investigadores y directores), de posibles jerarquías estético-artísticas entre la literatura y el cine, expresadas en el proceso adaptativo. Las variantes que se han distinguido son: 1) sobrestimación del oficio literario y la posibilidad de adaptar al cine la literatura; 2) ponderación del oficio literario en detrimento de las versiones; 3) sobrevaloración del oficio cinematográfico y la posibilidad de adaptar como criterio argumental; 4) consideración desmedida de la creación original en el cine en detrimento de las adaptaciones; 5) desestimación de toda relación (y, por tanto, de toda jerarquía) entre literatura y cine, negando así la posibilidad de adaptar; y 6) desaprobación de todo rango entre literatura y cine, valorando su relación, por medio de las transposiciones, como mutuamente aportativa.

Por lo general, los criterios de los escritores se centran más en las relaciones literatura/cine y no tanto en las adaptaciones específicamente. Entre estos escritores se encuentran Thomas Mann (1999), Carlos Fuentes (1965), Miguel Delibes (1986), Heinrich Mann (1999) y Graham Greene (s.a., 1967, pp. 4-5), aunque también es cierto que algunos de sus criterios se sustentan en una extraña ambigüedad. En virtud de ella, algunos escritores, por momentos, parecen partidarios también de la tendencia que supone una superioridad del cine sobre la literatura (variante 3 del proceso adaptativo). Se trata de verdaderos cinéfilos, como Gabriel García Márquez (1983) y Jorge Goldenberg (citado por Caballero, 1994). Y, más allá de la frontera de lo puramente neutral, están los que no adoptan posturas claramente definidas en este sentido, a pesar de haber sido protagonistas directos, en muchos casos, del entrecruzamiento entre ambas artes. Entre estos pudiera mencionarse a: Mario Benedetti (1993), William Faulkner (1999), Marguerite Duras (s.a., 1967, pp. 3-4) y Jorge Semprun (s.a., 1967, pp. 5-6).

Otra de las perspectivas -desde la que ha sido abordado el tema de las adaptaciones de obras literarias al cine- es la de los directores, máximos responsables del filme en todas sus facetas. Para no pocos de ellos es evidente la independencia de ambas manifestaciones, sin superioridades o dependencias, con criterios orientados hacia lo que requiere cada una de la otra. Aunque sus opiniones sean a veces contrarias y resulte muy difícil la tarea de agruparlas según sus puntos coincidentes, se ha podido apreciar, en la bibliografía consultada, que la problemática acerca de si existe o no superioridad estética del cine sobre la literatura (o viceversa), no es un tema que revista grandes atractivos para los cineastas. Sus criterios siguen tres direcciones principales: 1) existe influencia de la literatura sobre el cine; 2) no existe influjo de la literatura sobre el cine; y 3) existen influencias mutuas entre el cine y la literatura.

En el primer caso, se agrupan varios cineastas que, en cualquier momento de su carrera profesional, se han planteado la tarea de llevar a imágenes una obra literaria; potencialmente creen que existe una relación capaz de emparentar a ambas artes. Partiendo de esta máxima, excepto algunos importantes directores situados en la segunda dirección, la mayoría, a pesar de los matices, asume la influencia de la literatura en el cine. En el primer punto estaría como caso paradigmático Serguéi Mijáilovich Eisenstein (1977). 
Otros se inclinan por la vertiente diametralmente opuesta, al negar toda relación entre estas artes y considerar como un error su búsqueda. Son ejemplos los casos de Alain Robbe-Grillet (citado por Saad, 2004) y Luis Buñuel (1982), para quien simplemente tal relación no existe y es un error buscarla. En la misma línea, pero con el matiz de la imposibilidad de una adaptación dado que son lenguajes diferentes y difíciles de conciliar, están el sueco Ingmar Bergman (1990) y el español Miguel Picazo (s.a., 1987).

Es preciso acotar que son los críticos y estudiosos sobre temas de literatura y cine quienes más han aportado al tema de la adaptación, abogando lo mismo por una superioridad del séptimo arte, en el caso de A. Dovchenko (1987) y A. Marimayov (1963), como por lo contrario, según el punto de vista de Georges Sadoul (1980) y Russel Lee (1969); e incluso por una equivalencia estética, según las ideas de Galvano Della Volpe (1978) y Pío Baldelli (1966). De hecho, se ha llegado a desestimar toda jerarquía (variante 6 del proceso adaptativo) con criterios como este:

El hecho de que las películas puedan ser adaptadas de novelas no prueba que en estos filmes predominen valores literarios, ni tampoco podemos asegurar que obras creadas para la pantalla estén libres de la influencia del teatro o de la novela (Lawson, 1986, p. 295).

Este punto de vista corresponde a una de las ideas esenciales expuestas por el estudioso John Howard Lawson, quien se ha centrado en las adaptaciones de novelas, sin llegar a generalidades que permitan un reconocimiento cabal del proceso. Más relevante es la teoría de Pío Baldelli, también muy difundida en los años sesenta, quien propone cuatro posibles relaciones entre una adaptación cinematográfica y el texto literario que le sirvió de base.

La primera es lo que él denomina el saqueo de la obra literaria, de la que se extraen la trama y los personajes con el objeto de vender más y, a menudo, este procedimiento va unido a procesos de simplificación como la síntesis del diálogo y del número de personajes, o la de todo el conflicto social, político y económico. La segunda posibilidad consigue que el cine esté al servicio de la obra literaria al difundir su conocimiento.

La tercera opción es lo que el investigador italiano denomina la aparcería entre cine y literatura, en la que el director intenta completar el texto literario con añadidos cinematográficos. La cuarta posibilidad corresponde a la plena autonomía del filme respecto al texto literario, es decir, se estaría ante aquellos casos en los que el director impone su signo personal al texto literario y consigue subordinar o distanciar la obra literaria del filme.

El texto escrito solo es el punto de partida. Para Baldelli es evidente que la posición del director cambia caso por caso, la fidelidad no implica necesariamente un minucioso traslado: dependerá de la dosis de inercia que lleva a descartar ciertos detalles complicados de la narración o a recorrer atajos de recursos fáciles que reducen o conservan demasiado pasivamente el texto original.

Por un lado, Baldelli (1966) expone los

[...] caminos a optar por parte del director en el proceso de transcripción para acercarse a la literatura: [...] limitarse a traducir para la pantalla el texto original, adecuándose pacientemente con el mínimo de alteraciones; profundizar el cuadro histórico que rodea el asunto; o bien comportarse a voluntad, filmando por ejemplo un nuevo filme (p. 35).

Por otro, este autor deja claro el sentido de la comparación entre literatura y cine:

Naturalmente, no se trata de que la comparación sirva para establecer la dependencia estética del filme con respecto al texto literario, ni cortando sobre el primero la medida del segundo, para reprochar al filme por desviarse y no ser como el texto literario; nos servirá en cambio para controlar, por medio de una prueba, la dirección y el sentido del filme (p. 38). 
A los mencionados puede agregarse otros enfoques. U. Eco (1981) considera que el punto de partida de todo pensamiento acerca de la adaptación de un texto literario al cine es el reconocimiento de las divergencias y la autonomía expresiva de cada uno de estos lenguajes. Block de Behar, Scruggs y Updike (citados por McFarlane, 1996) afirman que las mejores adaptaciones de la literatura al cine oscilan, cualquiera que sea el texto original, entre el descubrimiento de sus convenciones cinematográficas y la reflexión sobre las fronteras y posibilidades del mismo medio. Mientras, R. Giddings, S. Keith y Ch. Wensley (citados por McFarlane, 1996) opinan que no se puede dar una respuesta definitiva que explique el fenómeno adaptativo y el efecto que este pueda tener en la apreciación de la obra original.

Joaquín Aguirre Romero (1989), apoyado en la narratología, establece una teoría rigurosa y en buena medida exhaustiva que se concreta, básicamente, en la comparación entre el narrador literario y cinematográfico, y entre los personajes literarios y cinematográficos. Otros criterios complementarios son la comparación temática y las modificaciones espacio-temporales. La reflexión de este autor sobre la calidad del trabajo de adaptación y de la entidad estética del filme opta por dejar en suspenso el problema de la legitimidad o del logro estético de las adaptaciones.

Mayor interés tienen los análisis teórico-prácticos, es decir, aquellos que sirven en la práctica analítica para elaborar una metodología y una fundamentación teórica o, por el contrario, en los que se establece un marco teórico que, posteriormente, se aplica a casos concretos. Por ejemplo, Juan Miguel Company (1987) investiga la instancia enunciativa en los relatos naturalistas Ilevados al cine, con el marcado interés de desmitificar la transparencia del relato fílmico y hacer ver la voluntad implicadora del espectador en la ficción. Mientras, Jorge Urrutia (1975) analiza las transformaciones que tienen lugar en algunos fragmentos de Pascual Duarte y Nazarín.
Otros autores se han referido al proceso adaptativo: Jorge Urrutia (1992), Patrick Cattrysse (1994), Sergio Wolf (2001, p. 79), Antoine Jaime (2000, pp. 109-110) y María Elena Rodríguez Martín (2006). Sin embargo, esta última ofrece una revisión de las teorías sobre la adaptación cinematográfica y alcanza una sistematización al enfatizar en las vías de acceso más recurrentes a este campo de estudio: 1) las teorías sobre la fidelidad al original; 2) los modelos narratológicos para el estudio de las adaptaciones; y 3) la visión de la adaptación como dialogismo intertextual.

Con respecto a la primera, varios estudiosos han cuestionado y criticado el empleo de este término para referirse a las versiones de textos literarios al séptimo arte. A los mencionados, cabe agregar, entre otros, a John Howard Lawson, Daniela Berghahn, A. Helman y W. M. Osadnik, Marcela Patricia Restom Pérez, W. Iser, María Lourdes Cortés y Robert Stam. Este último, como solución y reemplazo del término fidelidad, propone traslación (Stam, 2000, p. 55).

Estos autores han centrado sus críticas en el lenguaje moralista relacionado con la terminología que se adhiere al concepto de adaptación -que ha dado pie a términos como infidelidad, traición, violación, deformación o vulgarización-, la cual consideran no ha evolucionado y continúa centrada en la fidelidad.

Asimismo, señalan que el tratamiento de este asunto debe dejar de preocuparse por el criterio de fidelidad al original y prestar más atención a la respuesta dialógica; es decir, a las lecturas, críticas y reescrituras del material previo. La noción de fidelidad presenta varios inconvenientes: primero, es cuestionable su existencia ya que en la adaptación está implícito un cambio de código y, por consiguiente, una diferencia en relación con el original.

Sin embargo, como ha señalado Francisco Pineda: "Algunos estudiosos se han ocupado de analizar y criticar la validez del discurso de fidelidad y el enfoque centrado en el texto original, pero no han formulado ningún método de análisis y estudio alternativo al enfoque mencionado" (Pineda, 2006, pp. 16-17). El intento de superar estos puntos de 
vista va a ser, por tanto, una constante en muchos estudios sobre adaptaciones.

En este artículo no debe entenderse la fidelidad como reproducción exacta, es un término que funciona únicamente en la distancia para demarcar las cercanías y las diferencias entre los dos textos. En este sentido, Sergio Wolf (2001) ha precisado que la palabra fidelidad podría ser útil si se la entiende como sinónimo de modo de apropiación, con respecto al sentido de las operaciones y a los caminos por los que transitó el cineasta para vincularse con el material literario.

En relación con el segundo campo de estudio, María Elena Rodríguez (2006) estima que los juicios en torno a una adaptación deben fundamentarse en razones de interés narratológico y cita en su trabajo consideraciones de otros estudiosos sobre la transposición en criterios de interés narrativo. Son estos: Rifkin, Lotman, McFarlane, I. Whelehan y Berghahn. El procedimiento defendido por ellos consiste en analizar y evaluar las soluciones que la película presenta para aquellos aspectos propios del relato escrito que son difíciles de transferir al cine y que, por tanto, constituyen el principal problema al que se enfrenta toda adaptación.

En general, los modelos para el estudio de las adaptaciones que pueden incluirse en la línea de la narratología ofrecen una metodología aplicable a casos concretos. Como señala acertadamente María Elena Rodríguez (2006): “En las opiniones de Berghahn y Whelehan hemos visto lo positivo de los modelos narratológicos, pero también la necesidad de completar estos análisis con otro tipo de consideraciones que vayan más allá de las estrictamente narratológicas" (Rodríguez, 2006).

Mientras, en el tercer campo de estudio, otros especialistas de las adaptaciones de obras literarias al cine han abogado por el enfoque intertextual. Entre ellos se destaca Ángel Vilanova (1986), quien fue uno de los primeros en Ilamar la atención, desde el punto de vista teórico, acerca del valor de la transtextualidad genettiana para el estudio de la adaptación. También Robert Stam, quien es incluido por Naremore (2000) en su compilación de artículos referidos al tema de la intertextualidad en el cine. Stam (2000, p. 54-55) realiza una crítica al lenguaje sobre la adaptación fílmica de novelas, y se concentra en el concepto de adaptación como dialogismo intertextual, remitiendo a Genette. María Lourdes Cortés (1999, p. 29), por su parte, hace dialogar también los textos literarios con los cinematográficos, observando la coherencia o el desfase entre las escrituras de ambos productos, no tanto como un problema moral, sino como un enfrentamiento de lecturas, es decir, como un vínculo hipertextual.

Estos autores apuntan hacia una tendencia dominante en estos estudios: el hecho de centrarse en la adaptación de novelas y olvidar otras manifestaciones literarias como el cuento. La casi totalidad de ellos elude comparar los originales con transformaciones. Asimismo, señalan que se debe prestar más atención a las lecturas, críticas y reescrituras del material previo. De manera que, en la consideración de Cattrysse (1994), no hay un método mayoritariamente aceptado para la adaptación cinematográfica (p. 37). En este sentido, merecen atención un conjunto de tesis doctorales consultadas que, si bien dejan claro la importancia de abordar el estudio de las adaptaciones como relaciones entre textos, amén de la perspectiva asumida por el investigador, aún son insuficientes por cuanto abordan el tema desde la perspectiva cinematográfica.

Entre las referidas investigaciones Ilama la atención la titulada Hacia una teoría de la adaptación: cinco modelos narrativos latinoamericanos, de Marcela Patricia Restom Pérez (2006). Para esta autora, en una adaptación se debe analizar el manejo y uso de las técnicas de edición, la composición de los planos, los puntos de vista, la capacidad de alternancia visual (el manejo de acciones simultáneas en distintos lugares) y cuestiones de la puesta en escena, música, efectos de sonido que constituyen el sistema enunciativo del filme. Como se observa, aboga por el medio cinematográfico, para lo cual centra su análisis en la actuación de los actores, la música, los efectos de sonido y las imágenes, las características del encuadre y la adecuación de 
la puesta en escena. Restom describe los intertextos no literarios que funcionan dentro del texto fílmico y no sujeta la película únicamente a los requerimientos de la novela para no continuar con la subordinación del cine ante la literatura.

De importancia para este trabajo son las consideraciones de José Luis Sánchez Noriega en su libro De la literatura al cine. Teoría y análisis de la adaptación (2000). Aunque este texto apenas se menciona en los estudios acerca de las adaptaciones de obras literarias al cine, son útiles las reflexiones de su autor en torno al proceso adaptativo y la noción de fidelidad a la obra original. Hay que destacar la definición que ofrece del término adaptación como:

El proceso por el que un relato, la narración de una historia, expresado en una forma de texto literario, deviene, mediante sucesivas transformaciones en la estructura (enunciación, organización y vertebración temporal), en el contenido narrativo y en la puesta en imágenes (supresiones, compresiones, añadidos, desarrollos, descripciones visuales, dialoguizaciones, sumarios, unificaciones o sustituciones), en otro relato muy similar expresado en forma de texto fílmico (Sánchez, 2000, p. 47).

El concepto adaptación en su acepción etimológica ofrece la idea de "acomodo", de ajuste entre dos cosas, téngase en cuenta que viene del prefijo latino ad- que significa "a" y del verbo aptare que remite a "acomodar", "ajustar". Su sentido general es "hacer que una cosa forme con otra unidad adecuada" (RAE, 2001). En la mayoría de los trabajos sobre este aspecto, el término remite específicamente al "acomodo" de un texto literario a otro medio artístico: la pantalla. Hay, por tanto, un vínculo al menos entre dos textos: el original, literario, y el adaptado, cinematográfico. Pero no ha sido homogénea la terminología empleada en relación con las adaptaciones.
Otros términos que se han utilizado en la bibliografía para denominar el complejo proceso de un pasaje de un texto escrito al formato cinematográfico son: traslación, versión, traducción, transposición, trasvase, transfiguración, reescritura, transmutación, variatio, concretización, hipertexto, transmodalización, transcodificación, transmodificación, transformación, transficcionalización, apropiación, transición de lenguajes, traspolación, recreación, condensación, síntesis, transplantación y transcripción.

A pesar de que el término adaptación ha merecido la crítica de varios intelectuales, ninguno de los otros utilizados hasta el momento lo ha desplazado. Precisamente, Sánchez Noriega (2000) ha insistido en señalar la ventaja del empleo del vocablo adaptación para referirse a este proceso, por ser el más empleado. Aunque no niega otras denominaciones. Así, apunta: "Las adaptaciones, trasposiciones, recreaciones, versiones, comentarios, variaciones o como quiera que se denominen los procesos por los que una forma artística deviene otra". (p. 23).

Se puede hablar, indistintamente, de adaptaciones para denominar el proceso más amplio de cambio de una obra en otra, que convencionalmente puede llamarse adaptación o transposición (adaptada o transpuesta), tal como sugiere Sánchez Noriega.

Por último, en relación con el empleo de este término, cuando en este trabajo se explica o define lo que es adaptación, se está definiendo, en primera instancia, un fenómeno, más que una palabra. Esto quiere decir que el peso o interés principal está puesto en el referente y no en el objeto léxico que le sirve de rótulo. De manera que, así como se ha optado por la palabra adaptación para dar nombre al fenómeno, se habría podido escoger algún otro de sus sinónimos sin menoscabo de la noción expresada. 


\section{CONCLUSIONES}

El análisis científico de las adaptaciones de obras literarias al cine conjuga siempre enfoques diversos que permiten arrojar luces sobre las complejidades que resultan del maridaje entre artes, y las variantes o especificidades de la adaptación.

Las adaptaciones fílmicas de textos literarios han demostrado ser un asunto polémico, de encontradas discusiones, teniendo en cuenta la diversidad de criterios que giran en torno a ellas. Los entendidos en las materias de cine y literatura continúan abordándola desde puntos de vista muy opuestos y, en ocasiones, bastante radicales. Aun cuando se agrupó a los expertos según su oficio y se ha referido el autor de este artículo a escritores, directores y estudiosos, se ha visto que dentro de cada subgrupo los criterios se contraponen. Entre los escritores están los que sobreestiman el oficio literario y la posibilidad de adaptar al cine la literatura, los que resaltan el oficio cinematográfico en detrimento de las adaptaciones, hasta los que desestiman toda jerarquía entre literatura y cine, tanto negando la posibilidad de adaptar, en unos casos, como valorando su relación por medio de las adaptaciones como mutuamente aportativa, en otros. Por su parte, los directores de cine analizados centran el problema adaptativo en relación con la influencia entre ambas manifestaciones artísticas. Pudo apreciarse que tanto consideran que existe influencia de las bellas letras sobre el séptimo arte y viceversa, como que existen influencias mutuas entre ambas.

Se observa, también, que los estudiosos se centran las teorías sobre la fidelidad al original, los modelos narratológicos para el análisis de las adaptaciones y la mirada de la adaptación como dialogismo intertextual. Sin embargo, ha faltado una concepción que desde la ciencia filológica integre los presupuestos narratológicos, el elemento de la hipertextualidad y el apego a los criterios de fidelidad/creatividad a la obra original, síntesis lograda en el análisis eventual, que permite el estudio del proceso transpositivo desde una perspectiva literaria.

Por tanto, el estudio del problema de las relaciones literatura/cine, de los antecedentes críticos y de la praxis sistematizadora, realizada a partir del análisis hipertextual, ha permitido constatar algunas limitaciones teórico-metodológicas del tema. Se observa el poco tratamiento de la relación de los escritores con el cine y su vinculación directa en el proceso creador del filme a través del guion, y no se han alcanzado puntos de vista comunes sobre el carácter literario o no de aquel, base sustancial e insustituible de una producción cinematográfica acertada.

No obstante, a partir de este trabajo se puede inferir la importancia del guion para el estudio de las adaptaciones desde una perspectiva literaria, al valorarlo no como un elemento aislado de la película, y establecer el análisis del texto adaptado teniendo en cuenta la relación entre el original literario y el filme, determinar también el vínculo entre el texto de base y su guion, así como el lazo entre el guion y el texto literario original.

En ese sentido, este trabajo hace un recorrido sobre los estudios hipertextuales de las adaptaciones de obras literarias al cine, desde la perspectiva literaria (contrapuesta a la visión tradicionalmente cinematográfica), análisis que constituye una primera respuesta a las insuficiencias detectadas en los estudios valorativos al respecto. De ahí que la perspectiva literaria defendida resulte novedosa, por cuanto no se inscribe en la tradición que este tipo de estudios ha asentado en el ámbito teórico. Un modo valedero de alcanzar una adecuada comprensión, explicación e interpretación del proceso adaptativo de textos literarios en su tránsito a la pantalla, es el que puede realizarse siguiendo dicha perspectiva literaria, la cual puede definirse como el punto de vista que permite apreciar una película basada en una obra literaria a partir de presupuestos teóricos afines con el análisis literario, atendiendo a los valores que la cinta toma del original, los procesos que se operan en el tránsito 
del texto de base al guion cinematográfico, y de este al producto final de la realización, entendiendo el trasvase textual en que deviene la transposición como una relación hipertextual. Esta perspectiva literaria explicada es novedosa, por cuanto se fundamenta en: la hipertextualidad -concepto desarrollado por Gérard Genette (1989)-, el tratamiento adecuado de las categorías literarias, el uso de los procedimientos y tendencias adaptativas, y su resultado en la estructura del guion -principal puente hipertextual entre la obra original escrita y la fílmica-. Estos criterios permiten comprobar el buen aprovechamiento de la fuente literaria como soporte del entramado cinematográfico y el tributo que ello hace a la película.

El análisis realizado permitió determinar con claridad cuáles han sido los procedimientos adaptativos (supresión: eliminación de determinadas secuencias o partes de la historia; conservación: mantenimiento de ciertos aspectos de la trama; modificación: metamorfosis de algunas partes de los cuentos, por condensación o por ampliación; y añadidura: incorporación de contenidos ajenos a la obra literaria) y observar su aplicación al objeto de estudio ya que la manera en que se utilicen permite hablar de tendencias adaptativas predominantes en un proceso dado; y la terminología asumida para denominarlas se justifica en la naturaleza procesual de la adaptación.

Estas últimas se integran en una tipología novedosa en los estudios sobre las adaptaciones:

1. Paragenia: cuando se trata de respetar el contenido y la forma literaria con el máximo de detalles que permite el difícil proceso de traducción de códigos.

2. Contragenia: cuando se mantiene algún elemento formal -hecho, personaje- reconocible pero que traerá una propuesta, idea o análisis diferente del conflicto del original literario, y por consiguiente, un revestimiento distinto de los acontecimientos.

3. Morfotransgenia: se sitúa entre las dos anteriores; es cuando se conserva la esencia temática del libro inspirador, pero representado en una forma diferente, muchas veces más actualizado.

4. Sematransgenia: cuando se mantienen suficientes hechos, personajes y locaciones que permitan identificar al original literario, pero visto de tal forma que se trastrueque su esencia, como en esas obras fílmicas despojadas del fondo sociohistórico o filosófico, y en las parodias.

Cualquiera de los procedimientos y tendencias adaptativos definidos son estéticamente válidos, ya que todos constituyen caminos seguros hacia la adecuada estructuración del guion y, por tanto, de la película. La calidad de un producto audiovisual que asume los patrones de un modelo extraído de la literatura no dependerá de la tendencia adaptativa que predomine en su plan definitivo, como tampoco dependerá de los méritos estéticos de la fuente y el éxito o la popularidad que en virtud de aquellos haya alcanzado: solo el talento y la inteligencia con que guionista y cineasta hayan sabido conjugar los factores que determinan la adaptación, y el nivel de creatividad alcanzado en tal apropiación, podrán calificar la factura final de la obra surgida de sus manos. Por tanto, determinar los procedimientos y tendencias adaptativos facilita al estudioso comprobar en qué proporción fue utilizado el original literario, así como apreciar los aportes de este a la historia fílmica que se transpone. Es por tanto el producto fílmico en sí mismo una re-lectura de la fuente original, que se nutre de las características propias del cine como arte y como medio eficaz para la trasmisión de mensajes complejos.

Las adaptaciones de obras literarias al cine deberán seguir siendo asunto de polémica mientras tengan lugar, y estudios como el presente continuarán la teorización y adecuada profundización de los tópicos que aún la requieren. Resta eliminar los vacíos que aún subsisten, pero no con el fin de suprimir la polémica. Es tarea del investigador atizarla. $Y$ hoy son muchas más las publicaciones 
que podrían servir de punto de partida para ello. Basta tener un poco de voluntad, que a veces falta a quienes tienen el deber de hacer trascender, entre páginas, la obra de escritores y artistas: infatigables creadores del reino de la imagen.

\section{REFERENCIAS BIBLIOGRÁFICAS}

Aguirre R., J.M. (1989). Metodología para el análisis comparado de las adaptaciones cinematográficas de obras literarias. Madrid: Universidad Complutense-Facultad de CC. de la Información.

Baldelli, P. (1966). El cine y la obra literaria. La Habana: Ediciones ICAIC.

Benedetti, M. (1993). Cine y poesía. Cine Cubano, 138, 2-4.

Bergman, I. (1990). Cada film es mi último film. Cineguía, 3-4, 2-4.

BUÑUEL, L. (1982). Fragmentos de "El cine, instrumento de poesía". Cine Cubano, 102, 48.

Caballero, R. (1994). El guion es una faena insensata. Revolución y Cultura, 6, 30-33.

Cattrisse, P. (1994). The study of film adaptation: a state of the art and some "new" functional proposals. En: Actas del I Congreso internacional sobre trasvases culturales: literatura, cine y traducción (pp. 37-55). Vitoria: Servicio de Publicaciones de la Universidad del País Vasco.

Company, J.M. (1987). El trazo de la letra en la imagen. Madrid: Cátedra.

Cortés, M.L. (1999). Amor y traición; Cine y Literatura en América Latina. San José: Editorial de la Universidad de Costa Rica.

Delibes, M. (1986). Novela y cine. Revolución y Cultura, 2, 35-36.

Della Volpe, G. (1978). Crítica del gusto. La Habana: Arte y Literatura.

Dovchenko, A. (1987). Escribir para el cine. En: A. Fornet (comp.). El guionista y su oficio (pp. 20-32). San Antonio de los Baños: E. I. C. T. V.

Eco, U. (1981): Lector in fabula. Barcelona: Lumen.

EISENSTEIN, S.M. (1977). Dickens, Griffith y el cine actual. En: Anotaciones de un director de cine (pp.
240-315). Colección Testimonio. La Habana: Arte y Literatura.

FAULKNER, W. (1999). Mi experiencia en Hollywood. Cine Cubano, 146, 13-14.

Fuentes, C. (1965). El cine y el escritor. Cine Cubano, 31-32-33, 101-102.

García Márquez, G. (1983). La penumbra del escritor de cine. Cine Cubano, 105, 78-79.

Genette, G. (1989). Palimpsestos: la literatura en segundo grado. Madrid: Taurus.

JaIME, A. (2000). Literatura y cine en España (19751995). Madrid: Cátedra.

Lawson, J.H. (1986). El proceso creador del filme. La Habana: Arte y Literatura.

Lee, R. (1969). Cine, código e imagen. Pensamiento Crítico, 30, 148-154.

Mann, H. (1999). El ángel azul se me aparece. Cine Cubano, 146, 15-17.

ManN, T. (1999). El filme. Cine Cubano, 146, 11-12.

MarimaYov, A. (1963). Maiacovski sale a la pantalla. ICAIC, 6, 161-165.

McFarlane, B. (1996). Novel to film. An introduction to the theory of adaptation. Oxford: Clarendon Press.

Naremore, J. (ed.) (2000). Film Adaptation. Londres: The Athlone Press.

PinedA C., F. (2006). Del cuento a la pantalla: Transgresión e intertextualidad en "Peter Pan" (1953) y "Descubriendo nunca jamás" (2004). Recuperado de: http://www.cuentoenred.xoc.uam.mx (Consultado el 26 de enero de 2006)

Real Academia Española de la Lengua (2001). Diccionario de la lengua española. 22a. ed. Madrid: Espasa Calpe, S.A.

Restom P., M.P. (2006). Hacia una teoría de la adaptación. Cinco modelos narrativos latinoamericanos. Universidad Autónoma de Barcelona. Recuperado el 25 de enero de 2006 de: http://www.tdx.cat/ handle/10803/4873

Rodríguez M., M.E. (2006). Teorías sobre adaptación cinematográfica. Recuperado de: http://www.difusioncultural.uam.mx/casadeltiempo/100_jul_ sep_2007/casa_del_tiempo_num100_82_91.pdf 
S.A. (1967). Sobre el cine y la literatura responden: Agnes Varda, Marguerite Duras, Graham Greene, Jorge Semprun, Christiane Rochefort, Alain Resnais, Enrique Pineda Barnet, Eduardo Manet y José Massip. Cine Cubano, 40, 2-20.

S.A. (1987). Diálogo entre escritores y cineastas en Huelva. Panel integrado por los directores Miguel Littín, Miguel Picazo y Vicente Aranda y los escritores Alfredo Brice Echenique, Miguel Barnet y Salvador Garmendía. La Gaceta de Cuba, 24.

SAAD, F.A. (11 de diciembre de 2004). Del temor a la adaptación. Revista de Cultura $\tilde{N}, 5$.

SAdoul, G. (1980). Las maravillas del cine. La Habana: Gente Nueva.

SánChez N., J.L. (2000). De la literatura al cine. Teoría y análisis de la adaptación. Barcelona: Ediciones Paidós Ibérica, S. A.
Stam, R. (2000). Beyond Fidelity: The Dialogics of Adaptation. En: J. Naremore (ed.). Film Adaptation (pp. 54-76). Londres: The Athlone Press.

URRUTIA, J. (1975). La literatura española y el cine: Bases para un estudio. Madrid: Universidad Complutense-Facultad Filosofía y Letras.

URRUTIA, J. (1992). Literatura y comunicación. Madrid: Instituto de España/Espasa Calpe.

VILANOVA, A. (1986). La noción de transtextualidad y el estudio de las relaciones entre literatura y cine. En: Memorias XI Simposio de Docentes e Investigadores de la Literatura Venezolana (pp. 140-144). Mérida: Universidad de los Andes-Facultad de Humanidades y Educación-Instituto de Investigaciones Literarias "Gonzalo Picón Febres".

Wolf, S. (2001). Cine y Literatura, Ritos de Pasaje. Buenos Aires: Paidós.

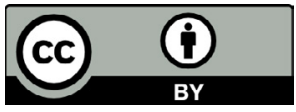

